\title{
Research on Land Surface Thermal-Hydrologic Exchange in Southern China under Future Climate and Land Cover Scenarios
}

\author{
Jianwu Yan, ${ }^{1,2}$ Baozhang Chen, ${ }^{1,3}$ Min Feng, ${ }^{1}$ John L. Innes, ${ }^{3}$ Guangyu Wang, \\ Shifeng Fang, ${ }^{1}$ Guang Xu, ${ }^{1,2}$ Huifang Zhang, ${ }^{1,2}$ Dongjie Fu, ${ }^{1,2}$ Huimin Wang, \\ Guirui Yu, ${ }^{4}$ and Xiaomin Sun ${ }^{4}$ \\ ${ }^{1}$ State Key Laboratory of Resources and Environmental Information System, Institute of Geographic Sciences and \\ Natural Resources Research, Chinese Academy of Sciences, Beijing 100101, China \\ ${ }^{2}$ Graduate University of Chinese Academy of Sciences, Beijing 100049, China \\ ${ }^{3}$ Department of Forest Resource Management, University of British Columbia, 2424 Main Mall, Vancouver, BC, Canada V6T $1 Z 4$ \\ ${ }^{4}$ Key Laboratory of Ecosystem Network Observation and Modeling, Synthesis Research Center of Chinese Ecosystem Research Network, \\ Institute of Geographic Sciences and Natural Resources Research, Chinese Academy of Sciences, Beijing 100101, China
}

Correspondence should be addressed to Baozhang Chen; baozhang.chen@igsnrr.ac.cn

Received 19 June 2013; Revised 29 September 2013; Accepted 17 October 2013

Academic Editor: Xiangzheng Deng

Copyright (C) 2013 Jianwu Yan et al. This is an open access article distributed under the Creative Commons Attribution License, which permits unrestricted use, distribution, and reproduction in any medium, provided the original work is properly cited.

\begin{abstract}
Climate change inevitably leads to changes in hydrothermal circulation. However, thermal-hydrologic exchanging caused by land cover change has also undergone ineligible changes. Therefore, studying the comprehensive effects of climate and land cover changes on land surface water and heat exchanges enables us to well understand the formation mechanism of regional climate and predict climate change with fewer uncertainties. This study investigated the land surface thermal-hydrologic exchange across southern China for the next 40 years using a land surface model (ecosystem-atmosphere simulation scheme (EASS)). Our findings are summarized as follows. (i) Spatiotemporal variation patterns of sensible heat flux $(H)$ and evapotranspiration (ET) under the land cover scenarios (A2a or B2a) and climate change scenario (A1B) are unanimous. (ii) Both $H$ and ET take on a single peak pattern, and the peak occurs in June or July. (iii) Based on the regional interannual variability analysis, $H$ displays a downward trend (10\%) and ET presents an increasing trend (15\%). (iv) The annual average $H$ and ET would, respectively, increase and decrease by about $10 \%$ when woodland converts to the cultivated land. Through this study, we recognize that land surface water and heat exchanges are affected greatly by the future climate change as well as land cover change.
\end{abstract}

\section{Introduction}

Global climate change characterized by global warming has put significant impacts on natural ecosystems and human society $[1,2]$. According to estimates, global climate will very likely continue to become warm in the next 100 years [3]. Many observed natural and biological systems' abnormal changes, such as species extinction, sea level rising, and frequent extreme weather events, as well as changes in plant and animal biological characteristics, have been linked to climate warming $[4,5]$. Therefore, a reasonable estimate of future climate change has become an important issue for scientists, public, and policy makers and a hot topic for improving the understanding of the climate system and the accuracy of future climate change projections.

Climate warming intensifies hydrothermal circulation as well and causes temporal-spatial variations of water and heat resources. It will further increase the frequency of hydrological extreme events and change the regional water and heat balances. In turn, water circulation and heat transport are important processes of each circle in the entire climate system. They directly affect the local climate, environments, and ecosystems and therefore play very important roles in climatic change and abnormity. Only detailed studies on their individual physical characteristics are carried out, can we recognize the formation mechanism of regional climates. 
Sensible heat flux $(H)$ and evapotranspiration (ET), respectively, reflecting the heat content and $\mathrm{H}_{2} \mathrm{O}$ vapor content in the atmosphere, are the two main components of the land surface water and heat fluxes which directly drive climatic change. Therefore, the allocation proportion of $H$ and ET will directly impact the climate change [6]. Analysis of their variations can enrich our knowledge of the interaction between terrestrial ecosystems and the atmosphere and thus promote us to better understand the regional and global climatic change processes.

Climatic change is a direct driving force of land surface thermal-hydrologic cycle. Many studies have assessed the impacts of climate change on energy transferring during historical periods [7-10]. However, recently some researchers began investigating the land-atmosphere energy exchange under future climate change scenarios [11]. The hydrological cycle and energy balance components caused by human activities at various temporal and spatial scales have also undergone ineligible changes. Human activities are mainly reflected in the underlying surface land use/cover change. Structure changes in the boundary layers caused by land cover change determine the spatial changes of sensible heat, latent heat, and moisture flux changes and then will alter the physical processes of the atmospheric boundary layers. At meso- and local scales, land use transformations are even likely to be among the first drivers of climatic change through altering local surface fluxes of radiation (e.g., albedo), heat, moisture (e.g., evaporation), and momentum (e.g., roughness length) [12-14]. It showed that simulated land cover conversion through climate in a Special Report on Emissions Scenarios (SRES) by the Intergovernmental Panel on Climate Change (IPCC) could have significant impacts on regional and seasonal climate, and some of these effects are the result of direct impacts of land cover change on local moisture and energy balances.

The majority of the previous related researches for history periods and future projections focused on the impact of water and heat exchange resulted from either climate change [15] or human activities [16-19]. Even if a few researches implemented a comprehensive analysis of the influences of the climate change and land cover change at regional scale, most of them just focused on qualitative aspects. Therefore, there is a need to assess the comprehensive influence of climate change and land cover change on the land surface water and heat fluxes so as to improve the capacity of forecasting future climate change.

On the underlying surface characterized by diverse composition, complex nature, and heterogeneous distribution like Southern China, the land-atmosphere interactions, as the key physical processes affecting climate anomalies, are even more comprehensive. Moreover, Southern China had experienced land cover change process of deforestation-reforestationreforestation in the past 30 years. With such a complex change process, only the analysis of land-atmosphere interaction processes from the mechanism level can improve our capability of modeling and predicting the future climate change in the Asian monsoon region.

In this study, the future spatiotemporal changes of $H$ and ET in Southern China were simulated using the ecosystem-atmosphere simulation scheme (EASS) model driven by the future projection data under climate change scenarios and land cover change scenarios to better understand the evolution pattern of water balance and net radiation budget. The research aims at providing a scientific basis for properly estimating the future climate dynamics under the context of global change.

The paper is organized as follows. The subsequent section describes the study area and methodology. Section 3 gives a short description of model forcing datasets and validation data. Results and Discussion are presented in Sections 4 and 5 , respectively. The final section provides a summary of the main findings.

\section{Study Area and Methodology}

2.1. Study Area. The study area, with various geomorphic types, is located between $104.42^{\circ} \mathrm{E}, 21.12^{\circ} \mathrm{N}$ and $120.59^{\circ} \mathrm{E}$, $31.25^{\circ} \mathrm{N}$, which covers the majority of Southern China, covering most parts of the Yangtze River and Pearl River (Figure 1). Totally, the study area is about $1.63 \times 10^{6} \mathrm{~km}^{2}$. Its elevation ranges from $0 \mathrm{~m}$ to $3702 \mathrm{~m}$ above the sea level. The YunnanGuizhou Plateau in the western area has the highest elevation and most of the other regions are at less than $500 \mathrm{~m}$ elevation except for Fujian province. The area is dominated by forests (40.97\%) which mainly include evergreen coniferous forests and evergreen broad-leaved forests. Then cropland accounts for $25.02 \%$. The distribution of soil types which are mainly comprised of sandy loam (16.32\%), clay loam (24.48\%), and loam $(24.51 \%)$ has a high degree of fragmentation. The subtropical climate is prevailed in the study area with the annual average temperature between $14^{\circ} \mathrm{C}$ and $20^{\circ} \mathrm{C}$ and annual average precipitation between $1100 \mathrm{~mm}$ and $1800 \mathrm{~mm}$. Rainy seasons are mainly from April to October here. The annual precipitation is imbalanced in different regions and interannual variations are also significant. Besides frequent natural disasters, this area has also experienced deforestation, afforestation, and reforestation processes during the past 30 years.

2.2. Model Description. An integrated land surface model, named ecosystem atmosphere simulation scheme (EASS), [20] is based on a single-layer vegetation canopy overlying a seven-layer soil, including physically-based energy and moisture fluxes transferring from the vegetation canopy and through it. The thermal dynamic in EASS is treated distinctively between vegetation and the underlying ground. Moreover, considering "big Leaf" models have inherent limitations [21], EASS stratifies the vegetation canopy as sunlit and shaded leaves. It has been referred to as a "twoLeaf" canopy model [20].

EASS can be run pixel by pixel over a defined domain, so it can be adopted at different scales based on available input data. Besides, EASS has flexible spatial and temporal resolutions, as long as the input data of each pixel is defined.

The typical characteristics of the model are briefly described as follows. (i) Energy, water, and carbon are simulated simultaneously based on explicit link among photosynthesis, evapotranspiration, and stomatal conductance. 


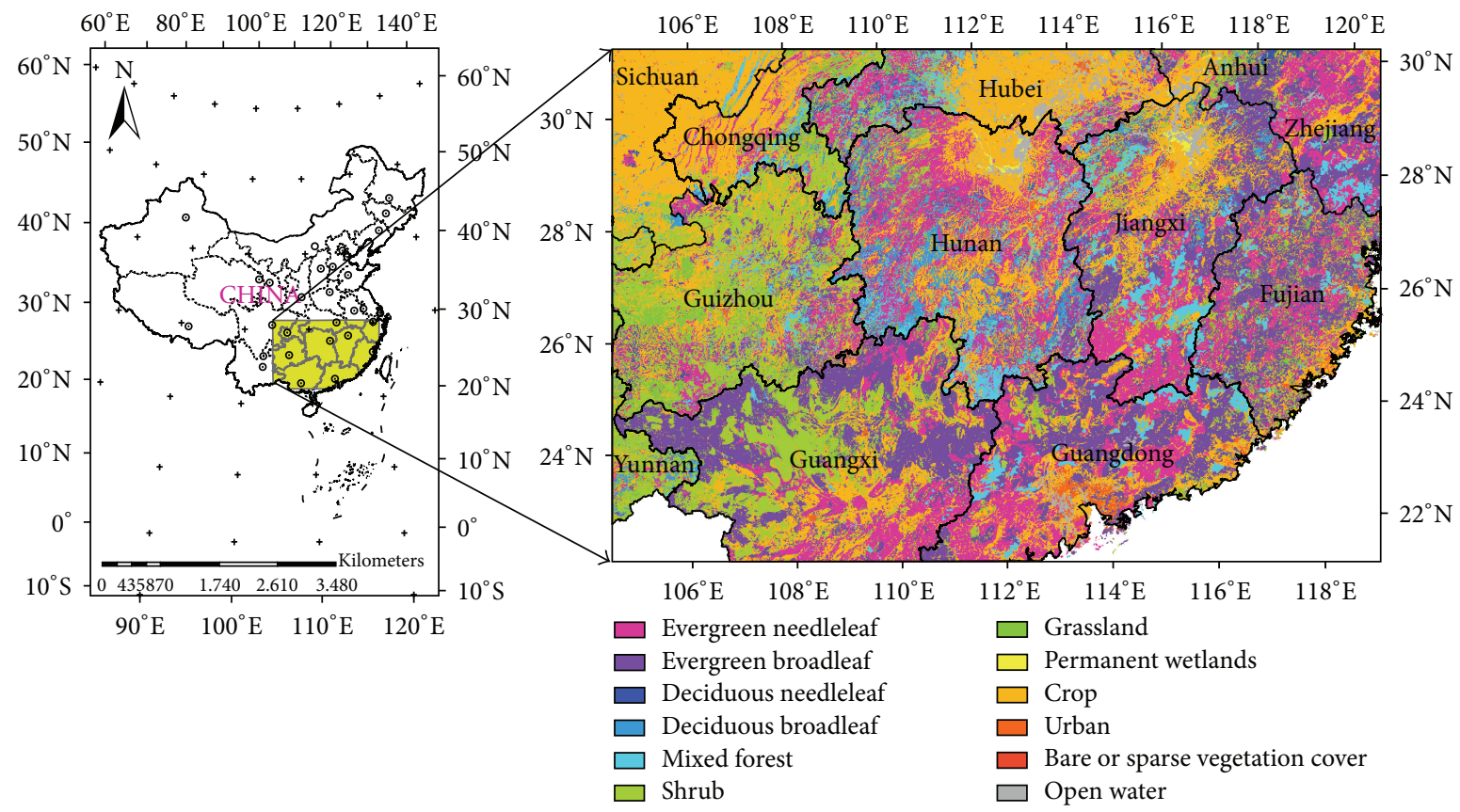

FIGURE 1: The location and land cover map in the year 2005 in Southern China.

(ii) Vegetation cover is treated as a single layer and the model stratified the vegetation canopy as sunlit and shaded leaves according to the solar zenith angle and a foliage clumping index $(\Omega)$ to minimize the biases from the "big Leaf" assumption. $\Omega$, in addition to LAI, is used to characterize the effects of three-dimensional canopy structure on radiation, water, and carbon fluxes. (iii) The key geoscience physical parameters (e.g., $\Omega$, land cover) of the model are parameterized based on remote sensing quantitative retrieval, and the regional simulation accuracy is improved. (iv) A multilayering scheme for energy exchanges and water transformation through the soil layers and/or snowpack (if present) is introduced in EASS. The number of snow and soil layers and the depth of each layer were user-defined according to soil physical structures, snow depth, and application objectives. (v) The dynamics of snowpack and freeze-thaw cycle in the soil profile are also emphasized in EASS. EASS is forced by near-surface meteorological variables at a reference level $z_{\text {ref }}$ within the atmospheric boundary layer, including surface air temperature, relative humidity, incident solar radiation, wind speed, and precipitation. The detailed descriptions are referred to in the paper by Chen et al. [20].

\subsection{Methodology}

2.3.1. Model Parameter Optimization. For future land cover scenarios, land cover classification system mainly includes cultivated land, woodland, grass land, build-up land, water area, wetland, nival area, desert, bare rock, and desertification land. This is a relative rough classification, making it impossible to correspond to the International GeosphereBiosphere Program (IGBP) classification acquired in EASS model. Therefore, the model needs to be improved and parameter optimization is required to match the existing land cover classification system for the future scenarios. Given that only one flux observation tower (QYZ) locates in this study area, we used the measured data from FLUXNET to optimize EASS model parameters over various plant function types and carried out model validation and evaluation.

2.3.2. Meteorological Data Preprocessing. The model driving meteorological data, including incoming shortwave radiation, air temperature, relative humidity, precipitation, and wind speed, were obtained from GCM-HadCM3, Hadley Centre for Climate Prediction and Research.

(i) Data Reading. Original format of the obtained meteorological data is rare (WTH format) and in irregular latitude and longitude grid cell, which adds great difficulty to the data processing work.

(ii) Spatial Downscaling. In view of the strong heterogeneity of the underlying surface, we took into consideration the vegetation, topography, and other factors closely related to meteorological conditions. Referring to Jia's methods [22], the $0.5^{\circ}$ grid cells were downscaled to obtain more accurate interpolation results.

(iii) Temporal Downscaling. The EASS model was run at hourly time steps. The obtained daily data need to be downscaled to hourly data. According to the dynamic characteristics of meteorological variables, different downscaling methods were adopted for different variables. Air temperature, relative humidity, 
and incoming solar radiation have certain diurnal variation rules but lack key control variables such as the maximum and minimum values. Therefore, the study referred to the hourly variability in a certain historical year. Moreover, the historical year was randomly selected, such as from 2000 to 2005, so as to avoid the constraints of a fixed reference year in the practical calculation process. We carried out downscaling to the daily meteorological variables for the future scenarios and eventually obtained relatively accurate hourly meteorological data series. Considering the suddenness and discontinuities of precipitation as well as variability and instability of wind speed, stochastic method was used to assign the daily average value to hourly value [23].

2.3.3. Validation Criteria and Model Evaluation. The critical parameters were optimized in the model to improve the model's capacity and applicability to varied land surface conditions. Employing the available global EC flux observation network data, the EASS model has been further validated and parameterized among a number of flux towers worldwide covering various plant functional types. The coefficient of determination $\left(R^{2}\right)$, root mean square error (RMSE, (1)), and index of agreement $(d,(2))$ are used to measure the accuracy of the model simulation:

$$
\begin{gathered}
\text { RMSE }=\left[\frac{1}{n} \sum_{i=1}^{n}\left(P_{i}-O_{i}\right)^{2}\right]^{0.5}, \\
d=1.0-\frac{\sum_{i=1}^{N}\left(O_{i}-P_{i}\right)^{2}}{\sum_{i=1}^{N}\left(\left|P_{i}-\bar{O}\right|+\left|O_{i}-\bar{O}\right|\right)^{2}},
\end{gathered}
$$

where $O$ is the observed data, $P$ is the model-simulated data, and $\bar{O}$ is the observed mean.

2.3.4. Experimental Design. This study used five-year time series (2010-2050) daily IPCC SRES A1B (medium emissions scenario) climate scenario data from the PRECIS forced by GCM-HadCM3 and two future land cover scenarios data (A2a_version2, B2a_version2), analyzed spatialtemporal variability of land surface thermal-hydrologic exchange in the next 40 years through two group experiment runs: (i) A1B climate scenario data and A2a_version2 land cover scenario data and (ii) A1B climate scenario data and B2a_version2 land cover scenario data. Then land surface water and heat flux changes were analyzed for the regions suffering from land cover conversion to further explore the impact of land cover changes on the water and heat fluxes.

\section{Data Preparation}

\subsection{Input Data}

3.1.1. Land Cover Data. Land cover scenario data used in this study were developed by Institute of Geographic Sciences and Natural Resources Research, Chinese Academy of Sciences. Combined with observational data of 735 meteorological stations in China and based on the climate change data of HadCM3 A1FI, A2a, and B2a, temporal-spatial variable raster data series of China HLZ (Holdridge life zone) ecosystem were obtained. Then, the marginal conversion model was established and run with these data and then China's future land cover change scenarios temporal series data were simulated. Detailed description of the production process can refer to Yue et al. [24]. Figure 2 shows the land cover change scenario in the next 40 years under A2a scenario. The land cover change scenario under B2a scenario was almost consistent with that under A2a scenario (data are not presented), except for a few changes of cultivated land and woodland (Figure 3).

3.1.2. Forcing Data. The atmospheric drivers for EASS included air temperature, relative humidity, precipitation, wind speed, and incoming shortwave radiation. The Providing Regional Climates for Impacts Studies (PRECIS) dataset was acquired from GCM-HadCM3 in Hadley Centre for Climate Prediction and Research with high resolution at $50 \times$ $50 \mathrm{~km}$ and then downscaled to $30 \times 30 \mathrm{~km}$ over our study regions using the method by Jia et al. [22]. PRECIS is widely used in China at present, mainly for climate simulations and climate change impact assessment, and a lot of work had been carried out for verifying its simulation capacity. PRECIS can be more reasonable to simulate temporal-spatial distribution pattern of Chinese regional climate variability [25-27]. Interannual changes of the two key forcing variables under A2a scenario are shown in Figure 4. The percentage changes under $\mathrm{B} 2 \mathrm{a}$ scenario are almost consistent with that under A2a scenario (data are not presented).

3.1.3. Other Input Data. 1:1,000,000 China soil database used in this study was built by Institute of Soil Science, Chinese Academy of Sciences [28]. The database consisted of soil spatial database, soil property database, and Chinese soil reference system. Majority of basic soil mapping unit in soil spatial databases are soil genus and included 12 soil orders, 61 soil groups, 235 subgroups, 926 soil type units, and 94,000 polygons. Soil property database contains 81 property fields, that is, soil depth, profile thickness, bulk density, organic matter content, gravel content, and so on. Valid connection of each corresponding polygon unit was created between soil profile data property database and spatial database with GIS platform.

All the driving data were unified at the same scale through rational scaling methods because the simulated experiments were based on spatial resolution of $30 \times 30 \mathrm{~km}$ grid. No future scenarios forecast LAI data yet till now. The research assumed that LAI maintains constant in the next 40 years, and LAI in 2005 was used as a reference to all the simulation experiments.

3.2. Flux Dataset. We chose the measured data in 2003 at QYZ $\left(26.733^{\circ} \mathrm{N}, 115.050^{\circ} \mathrm{W}\right)$, FR-Pue $\left(43.741^{\circ} \mathrm{N}\right.$, $\left.3.596^{\circ} \mathrm{W}\right)$, AT-Neu $\left(47.116^{\circ} \mathrm{N}, 11.320^{\circ} \mathrm{W}\right)$, CA-NS6 $\left(55.917^{\circ} \mathrm{N}\right.$, $\left.-98.964^{\circ} \mathrm{E}\right), \quad$ FI-Kaa $\left(69.141^{\circ} \mathrm{N}, 27.295^{\circ} \mathrm{W}\right)$, and US-Bo1 

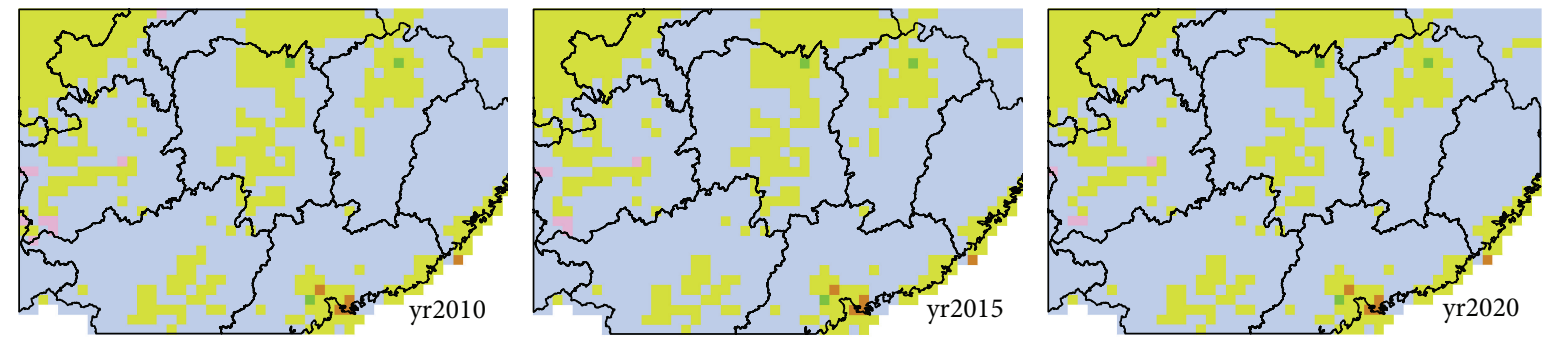

(a)
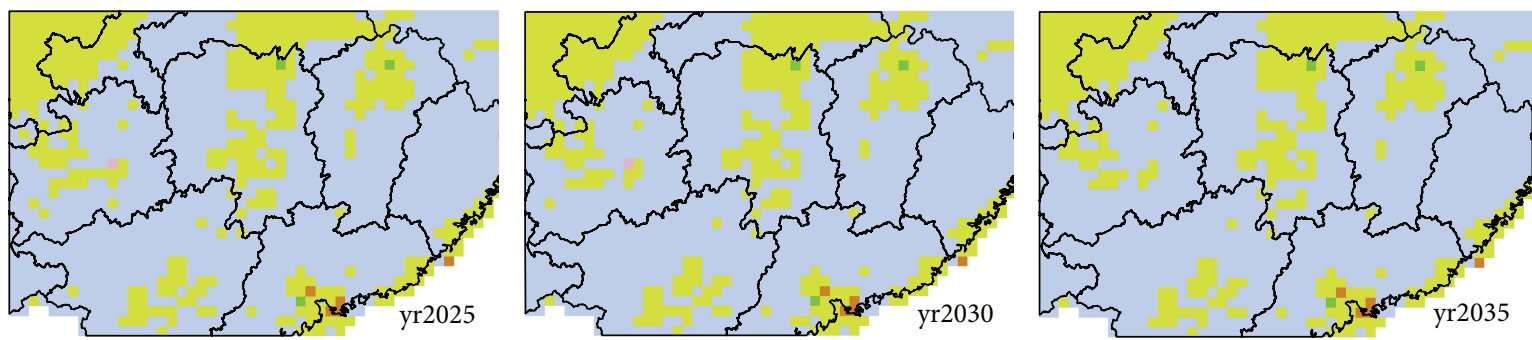

(b)
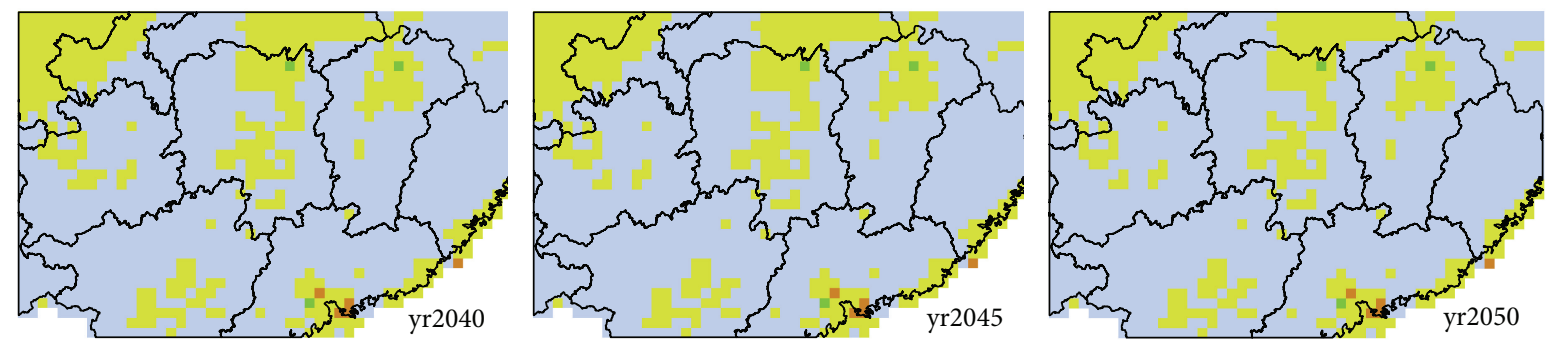

Cultivated land

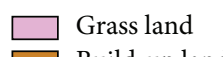

$\square$ Water area

$\square$ Nival area

Desert

Bare rock

Desertification land

(c)

Figure 2: Spatial dynamics of A2a land cover change scenario in the next 40 years.

TABLE 1: EASS validation results for $H$ and ET for several typical ecosystems.

\begin{tabular}{|c|c|c|c|c|c|c|c|c|c|c|}
\hline \multirow{2}{*}{ Station name } & \multirow{2}{*}{ Longitude } & \multirow{2}{*}{ Latitude } & \multirow{2}{*}{ Elevation $(m)$} & \multirow{2}{*}{ PFTs } & \multicolumn{3}{|c|}{$H\left(\mathrm{~W} \mathrm{~m}^{-2}\right)$} & \multicolumn{3}{|c|}{ ET $\left(\mathrm{mm} \mathrm{day}^{-1}\right)$} \\
\hline & & & & & $R^{2}$ & RMSE & $d$ & $R^{2}$ & RMSE & $d$ \\
\hline FR-Pue & 3.59 & 43.74 & 270 & $\mathrm{EBF}$ & 0.83 & 49.96 & 0.91 & 0.57 & 66.60 & 0.83 \\
\hline AT-Neu & 47.12 & 11.32 & 970 & Grassland & 0.76 & 85.93 & 0.55 & 0.91 & 16.87 & 0.96 \\
\hline FI-Kaa & 27.30 & 69.14 & 155 & Wetland & 0.76 & 21.93 & 0.95 & 0.71 & 19.58 & 0.83 \\
\hline US-bol & -88.29 & 40.01 & 219 & Crop & 0.65 & 68.27 & 0.82 & 0.91 & 37.55 & 0.87 \\
\hline QYZ & 115.05 & 26.73 & 111 & ENF & 0.94 & 36.18 & 0.88 & 0.83 & 29.16 & 0.86 \\
\hline CA-NS6 & -98.96 & 55.92 & 244 & Shrub & 0.57 & 24.49 & 0.89 & 0.81 & 29.57 & 0.92 \\
\hline
\end{tabular}

Note. EBF is evergreen broadleaf forest; ENF is evergreen needleleaf forest.

$\left(40.006^{\circ} \mathrm{N},-88.290^{\circ} \mathrm{W}\right)$ (Table 1$)$ which located at different plant functional types from the FLUXNET and ChinaFLUX network for model validation.

The meteorological variables for model inputs including incoming shortwave radiation, air temperature, and relative humidity, were measured in 2003 with eddy covariance (EC) systems at the towers, and all of them were recorded at
30 minute intervals. Precipitation above the canopy was recorded with a rain gauge. $3 \mathrm{D}$ wind speed was measured with a $3 \mathrm{D}$ sonic anemometer, and the half-hourly surface fluxes were measured simultaneously with the EC system. More detailed descriptions on observation of these sites can be found online at http://www.chinaflux.org/ and http://www.fluxdata.org/. 


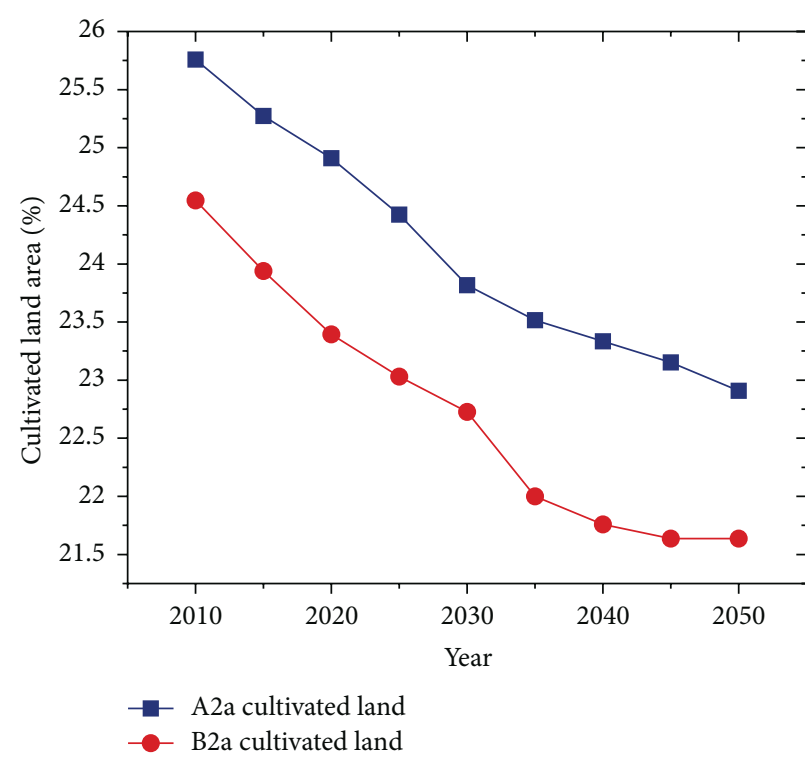

(a)

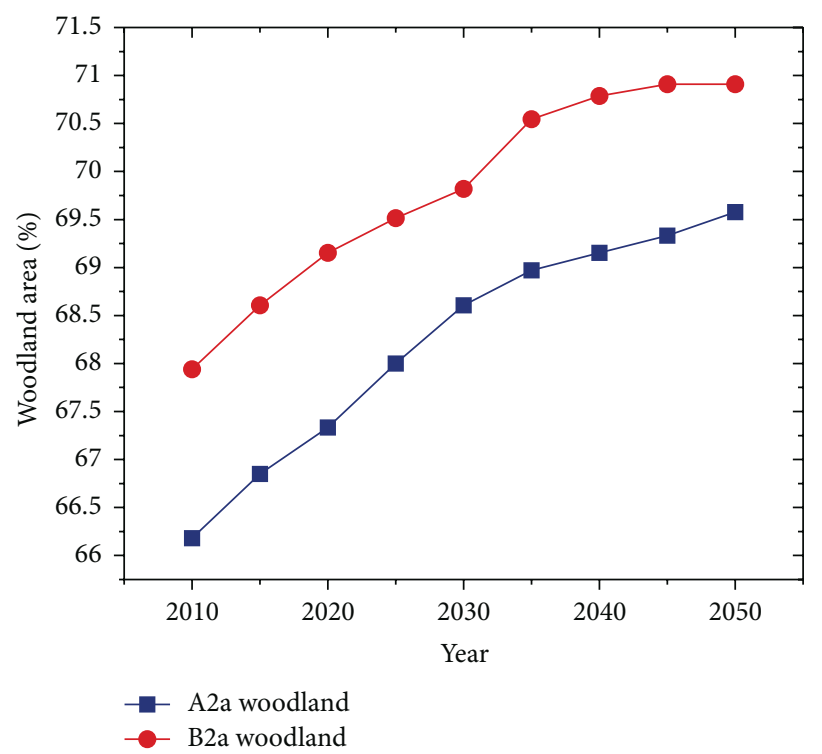

(b)

FIGURE 3: Interannual change of cultivated land and woodland area percentage in the next 40 years under A2a and B2a land cover change scenarios.

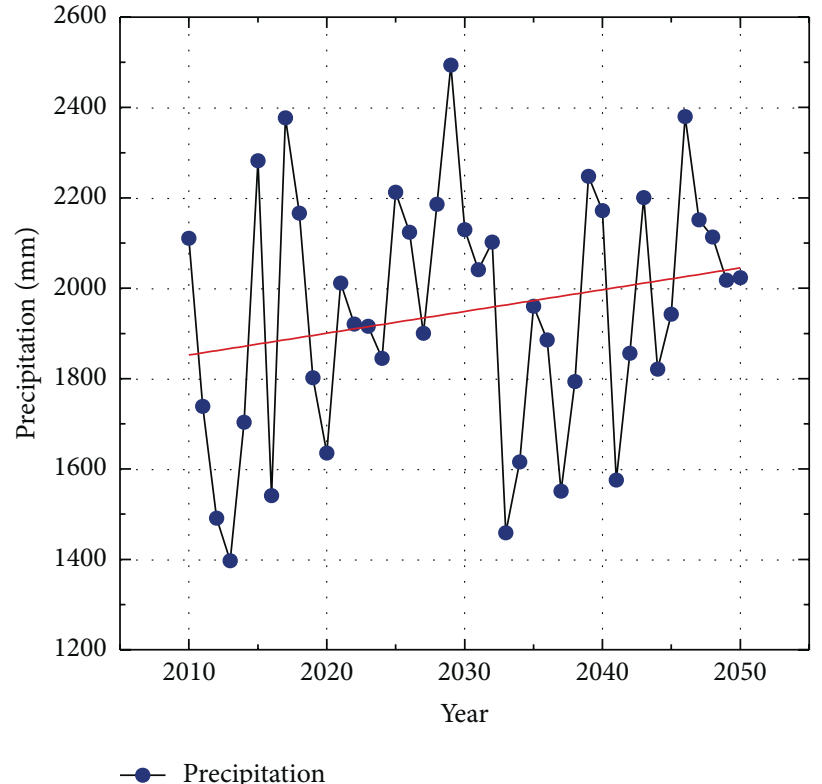

(a)

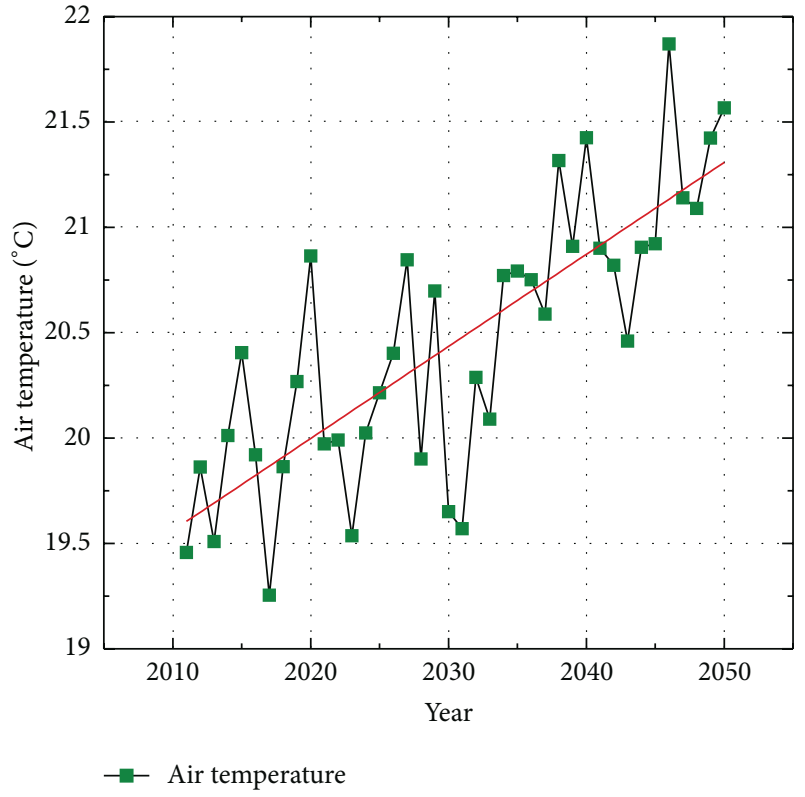

(b)

FIGURE 4: Interannual change of precipitation and air temperature in the next 40 years under A2a scenario.

\section{Results}

4.1. Validation of the Model. In order to validate the model, land surface experiments were performed at the tower sites mentioned above. Simulated $H$ and ET agree well with the observations throughout the year (Table 1). The coefficients of determination $\left(R^{2}\right)$ for the six stations located in different typical ecosystems are mostly above 0.7 , and the values of indexes of agreement $(d)$ are typically higher than 0.8 , except for $H$ in grassland. The EASS model performed well overall and is acceptable across different ecosystems. More evaluation of the EASS model can be referred to in Chen et al. [20] paper published in 2007.

4.2. Temporal-Spatial Variation of Water and Heat Fluxes under Land Cover Scenario. We analyzed regional change of $H$ in the next 40 years based on the value obtained in 2010 . Figure 5 demonstrates that interannual changes in spatial 

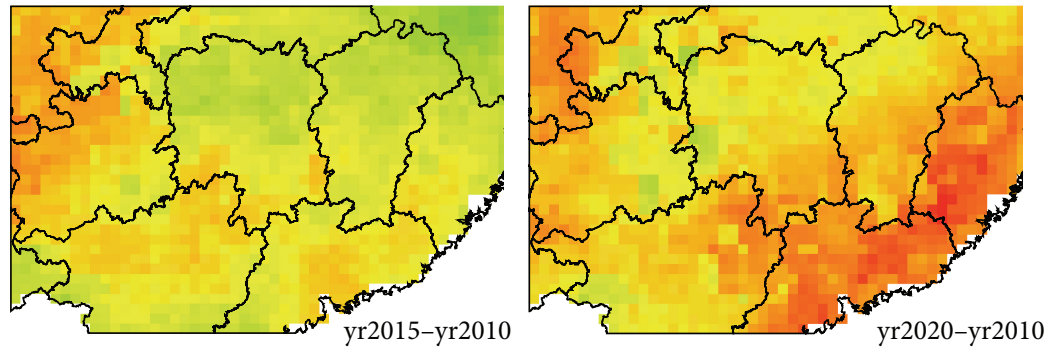

(a)
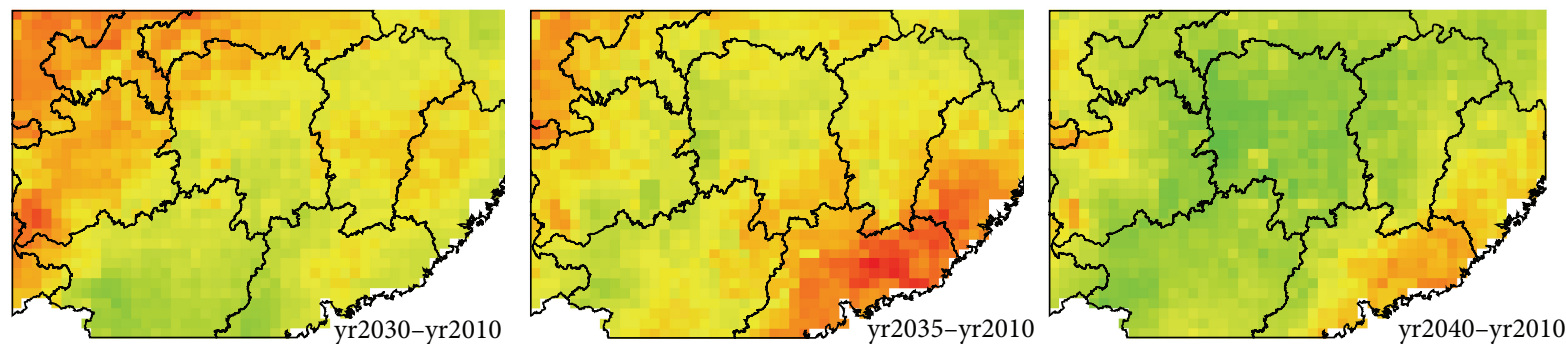

(b)
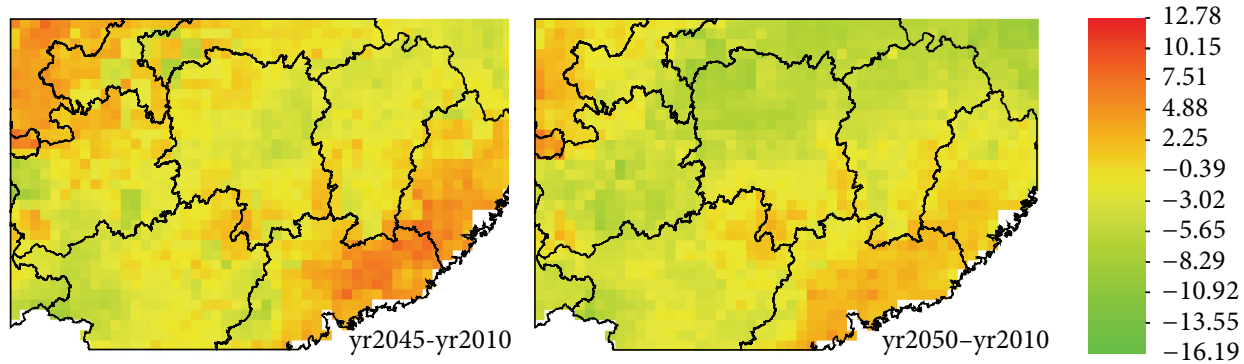

(c)

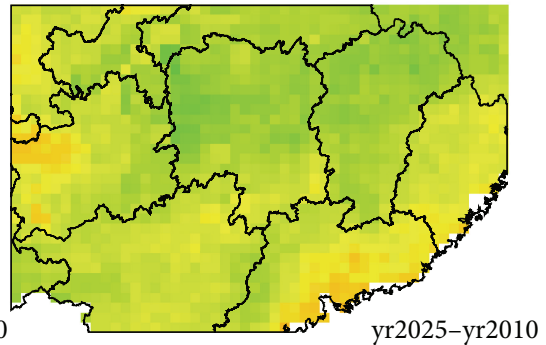

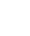



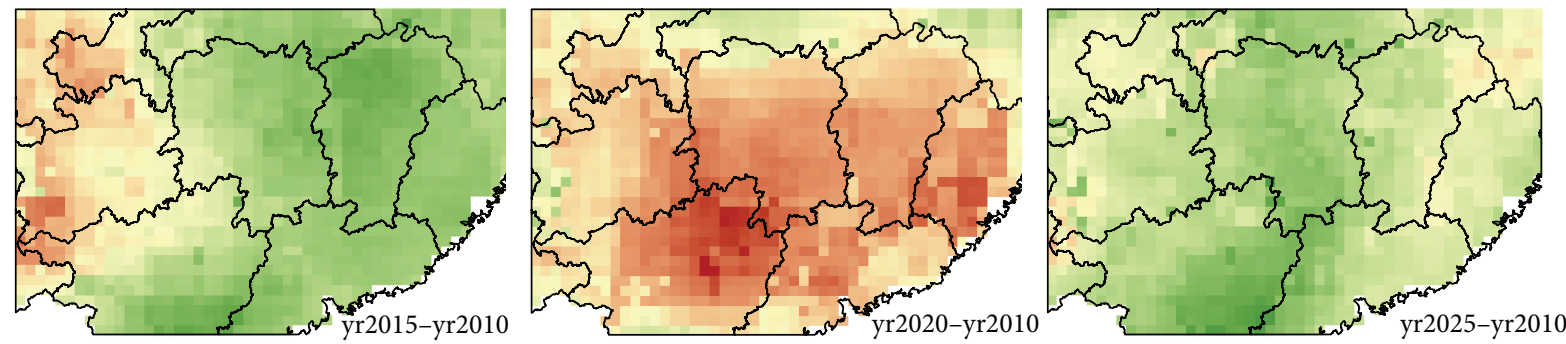

(a)
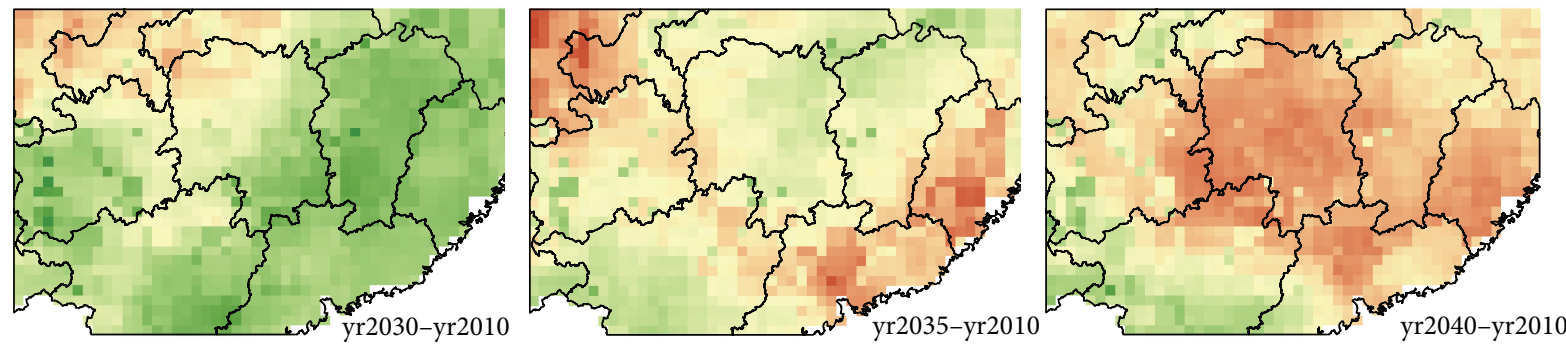

(b)
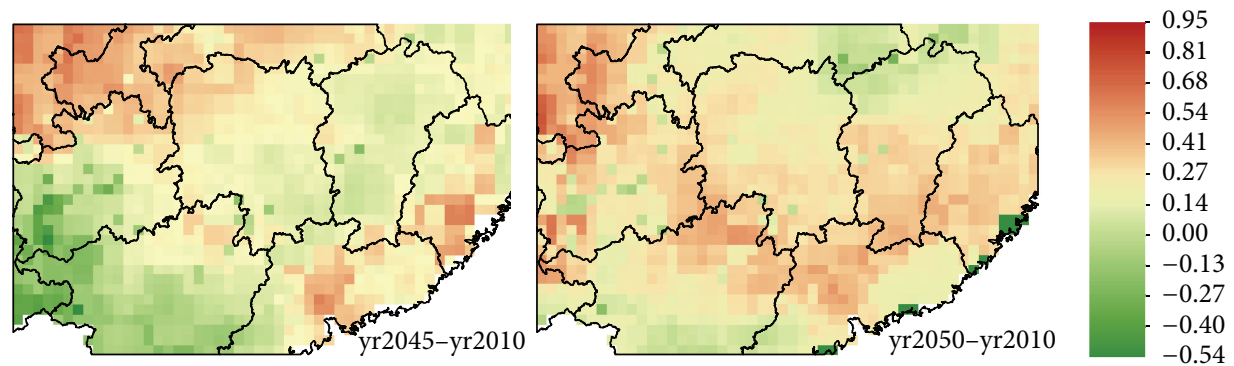

(c)

FIGURE 6: Interannual spatial dynamic of ET $\left(\mathrm{mm} \mathrm{year}^{-1}\right)$ in the next 40 years under A2a scenario.

4.3. Impact of Land Cover Change on Water and Heat Exchanges. In order to explore the impact of land cover changes on land surface water and heat fluxes, we chose a region where significant change occurred locates in Guizhou province (red circle area in Figure $9,107.55^{\circ} \mathrm{E}, 26.59^{\circ} \mathrm{N}$ ). This area is cultivated land under A2a land cover scenario in 2040 and transfers to woodland in the same year under B2a land cover scenario. We abstracted the daily $H$ and ET and analyzed the daily change as shown in Figure 9. $H$ under A2a scenario is basically higher than the simulated result under B2a scenario at any time of the year, and the average annual data under A2a scenario is higher by $9.4 \%$ than the value under B2a scenario. Opposed to $\mathrm{H}$, ET under A2a scenario decreases by approximately $9.4 \%$ compared with the value under B2a scenario. Similar findings were also reported by previous studies [28].

\section{Discussion}

Just concerned with climate change itself, air temperature and precipitation would increase in the next 40 years (Figure 4 ), and generally, canopy temperature would increase, and consequently $H$ would increase. However, the simulation results are not as this (Figure 8). The main reason may be that land cover transformation would also occur in the next 40 years. From Figure 3, we can see obviously that the woodland area increases continually, and would increase about $5 \%$ and $4.4 \%$ for the two land cover scenarios from 2010 to 2050, respectively. We also found that cultivated land area almost reduced the same proportion as increasing woodland area; that is, the increasing woodland area is mainly from the the decreasing of cultivated land area. Generally, the increased woodland area will lead to increased ET $[29,30]$.

As we all know, not only net radiation includes shortwave radiation balance but also long-wave radiation which is proportional to the fourth power of the temperature. Net radiation is equal to the sum of $H$, latent heat flux, and ground heat flux $(G)$ ( $G$ value is generally small). In order to maintain energy balance, $H$ is bound to decrease when ET increases. The surface net radiation increases with woodland coverage ratio increasing. In our simulation, land cover transferring from cultivated land under A2a land cover scenario to woodland under $\mathrm{B} 2 \mathrm{a}$ land cover scenario, $H$ decreases by $10 \%$ and ET increases by $15 \%$. The decrease in $H$ is insufficient to the increase in ET. This 5\% deficiency may be due to an increase of net radiation. 


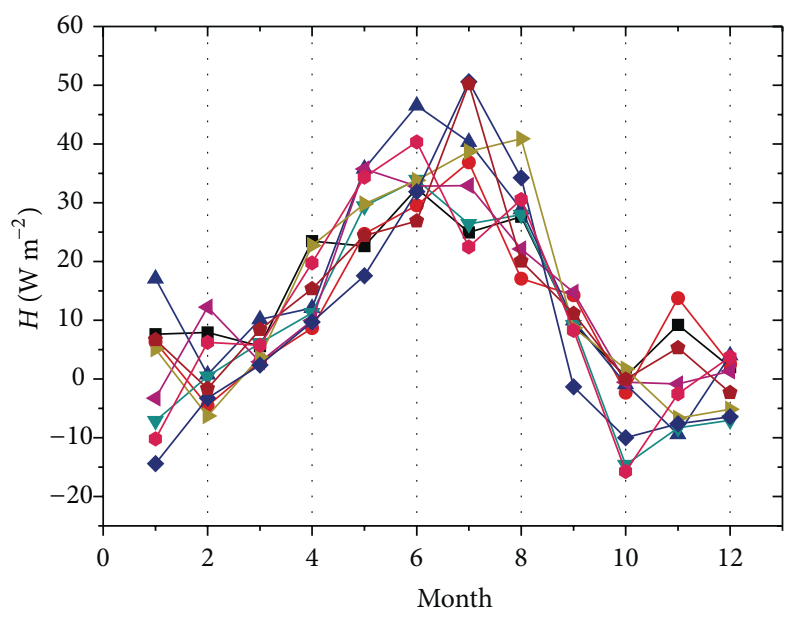

(a)

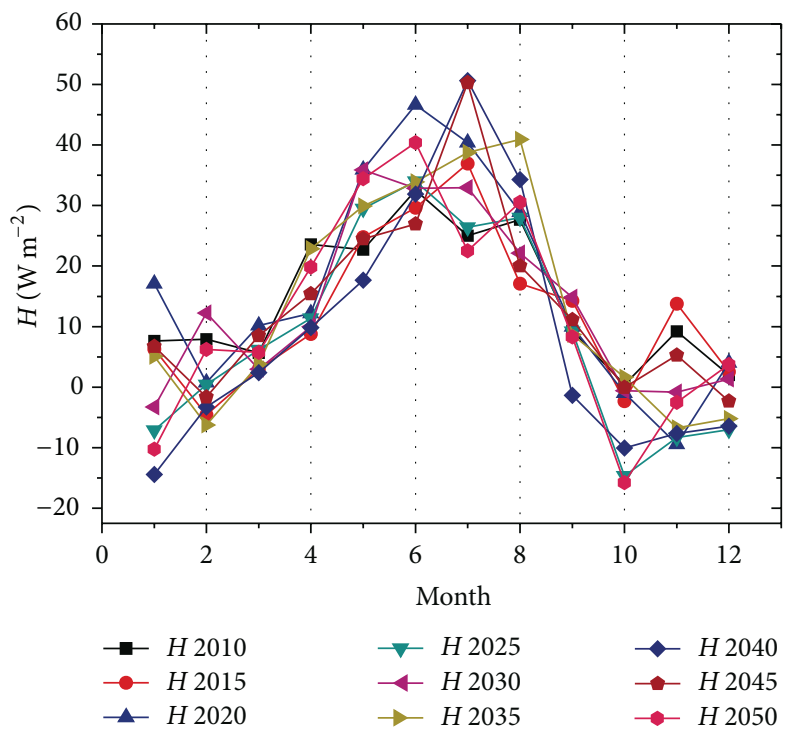

(c)

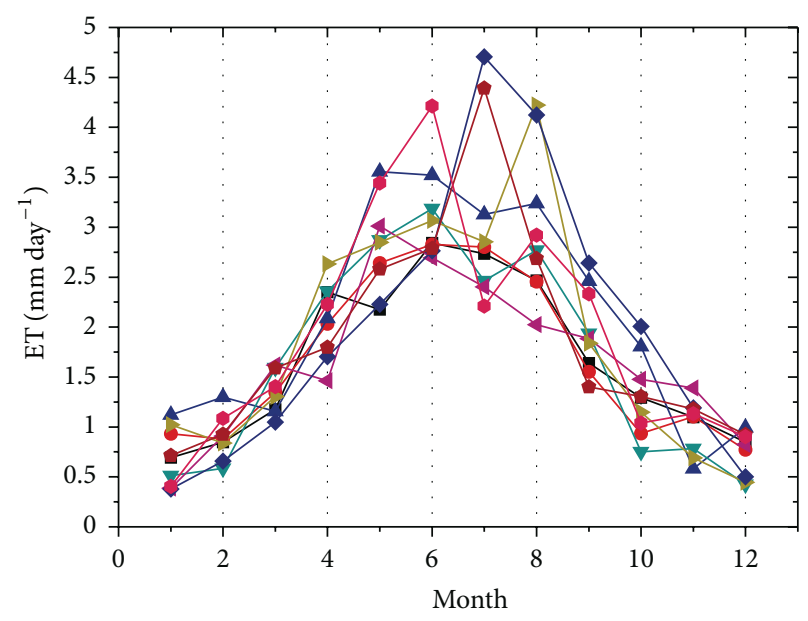

(b)

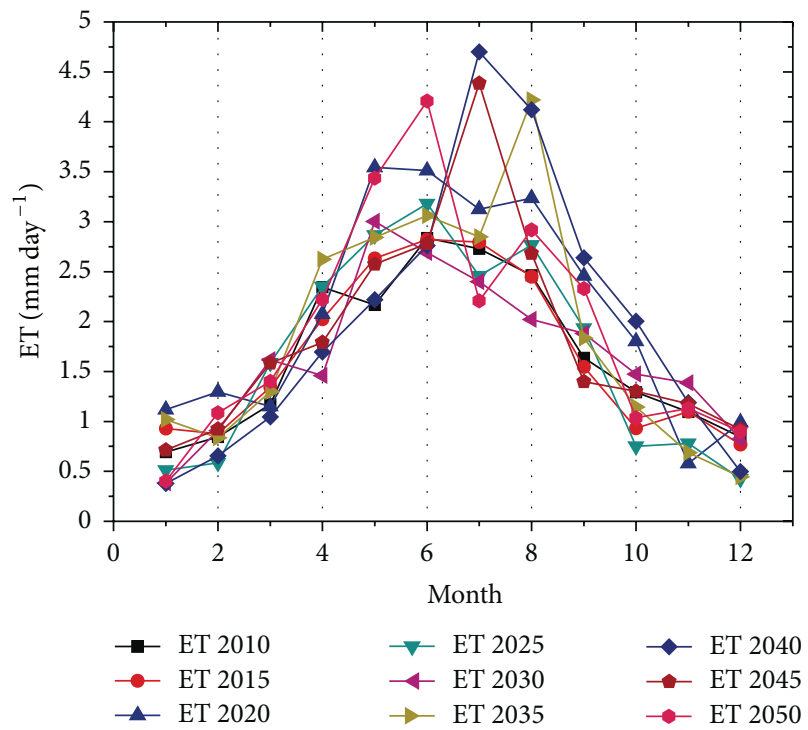

(d)

FIGURE 7: Seasonal variability of $H$ and ET in the next 40 years. (a) and (b) for the simulated results under A2a scenario; (c) and (d) for the simulated results under B2a scenario.

The results also could be explained from the view of plant physiology. Forest vegetation has a high photosynthetic capacity. Absorbed solar energy would be converted to $\mathrm{H}_{2} \mathrm{O}$ vapor through photosynthesis process and dissipated into atmosphere from plants (canopy and leaf). This process needs to absorb heat, and consequently plants will reduce their surface temperature. With the leaf temperature decreasing and air temperature increasing, $H$ would be decreased. Moreover, woodland, as a thermostat, has a cooling effect, and consequently canopy temperature would decrease through evaporative cooling.

\section{Conclusion}

In this study we addressed the comprehensive impact of climate change scenario and land cover change scenario on future land surface water and heat fluxes with a material circulation and energy flow coupled land surface model EASS and obtained the following preliminary conclusions through the above two simulation experiments.

(i) The simulated results under the two land cover scenarios show that spatial variation of $H$ and ET simulated in the two above runs in the next 40 years is almost consistent and this change pattern is reflected more intuitively from the regional average annual change. (ii) The seasonal variations demonstrated that the simulated results are almost consistent under the two scenarios except for $H$ appearing small peaks in November in the simulated years. Besides, there exist huge fluctuations among the simulated years. (iii) Through annual variation analysis of the two scenarios, $H$ has a decreasing trend by about $10 \%$ and ET has an increasing trend by about $15 \%$ in the next 40 years. (iv) Spatiotemporal distributions of land surface water and heat would suffer greatly from the future climate change, whereas the impact of the regional 


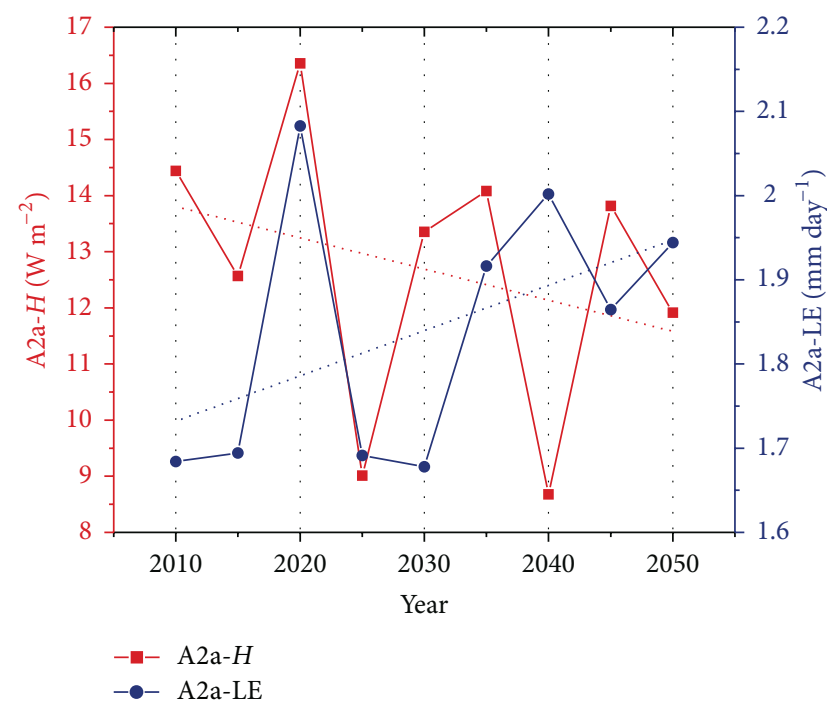

(a)

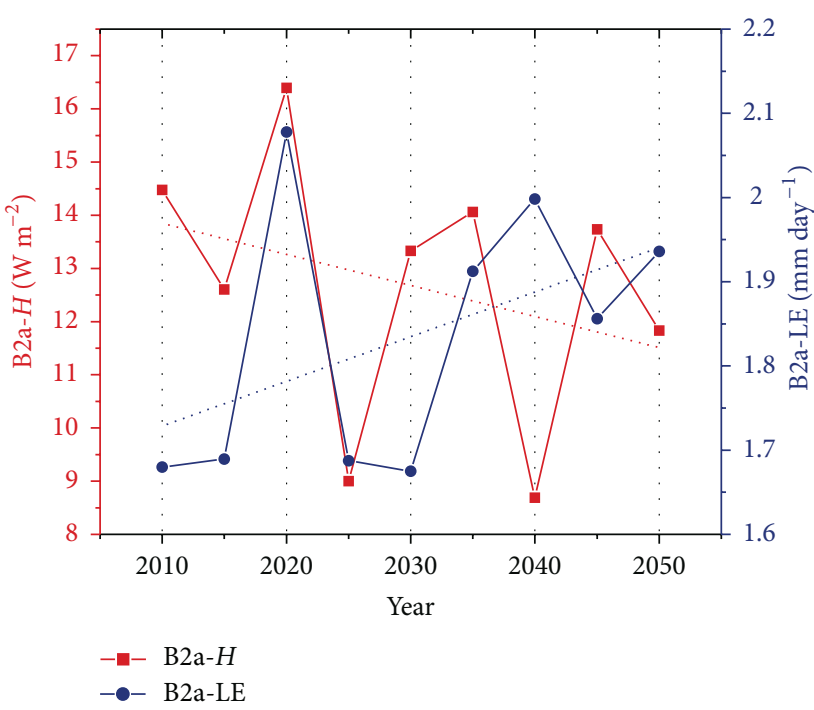

(b)

Figure 8: Interannual average areal $H$ and ET in the next 40 years.
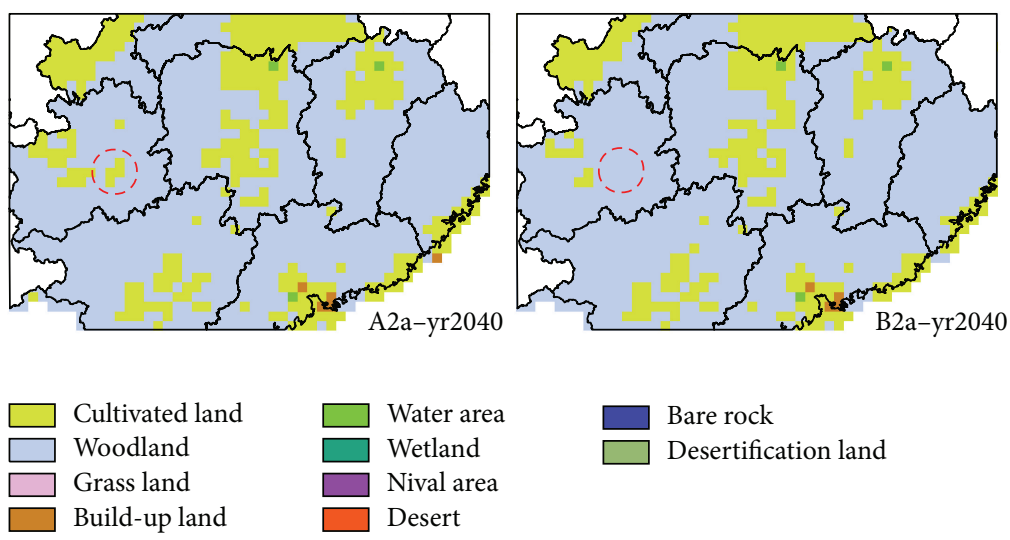

(a)

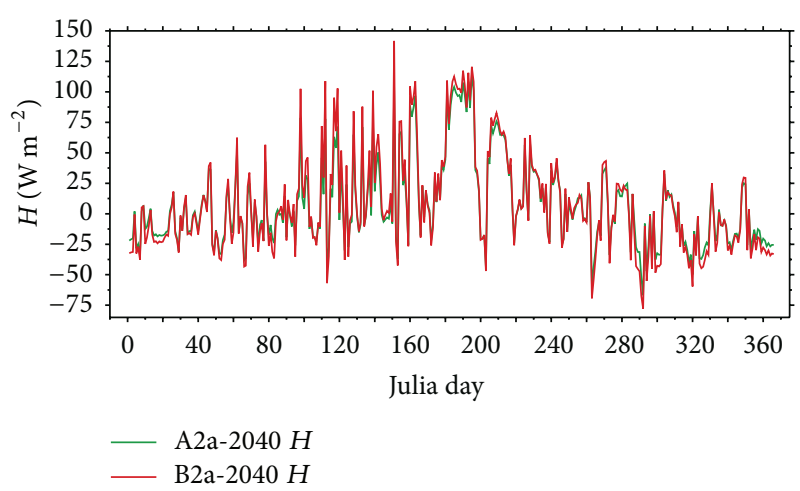

(b)

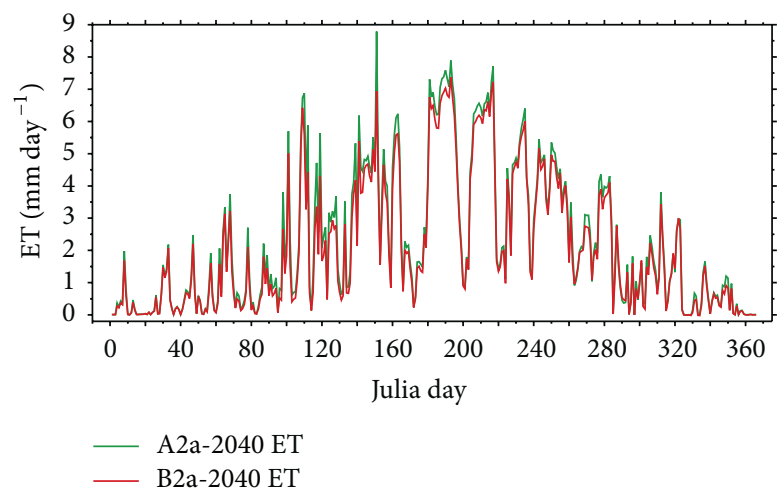

(c)

FIGURE 9: Analysis of the impact of land cover scenario process on water and heat exchange for the year 2040 located in the east of Guizhou province. 
magnitude from the land cover change scenarios cannot be neglected.

\section{Acknowledgments}

This research is supported by the National Basic Research Program of China (973 Program) (no. 2010CB950904 and no. 2010CB950902), by the research Grant (2012ZD010) of Key Project for the Strategic Science Plan in IGSNRR of CAS, a Research Plan of LREIS (O88RA900KA), CAS, the research Grants (41071059 and 41271116) funded by the National Science Foundation of China, a research grant named "Adaptation of Asia-Pacific Forests to Climate Change" (Project no. APFNet/2010/PPF/001) founded by the Asia-Pacific Network for Sustainable Forest Management and Rehabilitation, and "One Hundred Talents" program funded by the Chinese Academy of Sciences. The authors are grateful to data from FLUXNET and ChinaFLUX. The authors also thank Xiangzheng Deng and three reviewers for their useful comments and suggestions which significantly improved this paper.

\section{References}

[1] G.-R. Walther, E. Post, P. Convey et al., "Ecological responses to recent climate change," Nature, vol. 416, no. 6879, pp. 389-395, 2002.

[2] D. D. Zhang, P. Brecke, H. F. Lee, Y.-Q. He, and J. Zhang, "Global climate change, war, and population decline in recent human history," Proceedings of the National Academy of Sciences of the United States of America, vol. 104, no. 49, pp. 19214-19219, 2007.

[3] Intergovernmental Panel on Climate Change, "Climate change 2007: the physical science basis," in Contribution of Working Group I to the Fourth Assessment Report of the Intergovernmental Panel on Climate Change, S. Solomon, D. Qin, M. Manning et al., Eds., p. 996, Cambridge University Press, Cambridge, UK, 2007.

[4] G. A. Meehl, W. M. Washington, W. D. Collins et al., "How much more global warming and sea level rise?" Science, vol. 307, no. 5716, pp. 1769-1772, 2005.

[5] S. Planton, M. Déqué, F. Chauvin, and L. Terray, "Expected impacts of climate change on extreme climate events," Comptes Rendus Geoscience, vol. 340, no. 9-10, pp. 564-574, 2008.

[6] G. A. Ban-Weiss, G. Bala, L. Cao, J. Pongratz, and K. Caldeira, "Climate forcing and response to idealized changes in surface latent and sensible heat," Environmental Research Letters, vol. 6, no. 3, Article ID 034032, 2011.

[7] A. H. Goldstein, N. E. Hultman, J. M. Fracheboud et al., "Effects of climate variability on the carbon dioxide, water, and sensible heat fluxes above a ponderosa pine plantation in the Sierra Nevada (CA)," Agricultural and Forest Meteorology, vol. 101, no. 2-3, pp. 113-129, 2000.

[8] K. B. Wilson, D. D. Baldocchi, M. Aubinet et al., "Energy partitioning between latent and sensible heat flux during the warm season at FLUXNET sites," Water Resources Research, vol. 38, no. 12, pp. 1294-1305, 2002.

[9] L. Gu, T. Meyers, S. G. Pallardy et al., "Direct and indirect effects of atmospheric conditions and soil moisture on surface energy partitioning revealed by a prolonged drought at a temperate forest site," Journal of Geophysical Research D, vol. 111, no. D16, Article ID D16102, 2006.
[10] P. Krishnan, T. P. Meyers, R. L. Scott, L. Kennedy, and M. Heuer, "Energy exchange and evapotranspiration over two temperate semi-arid grasslands in North America," Agricultural and Forest Meteorology, vol. 153, pp. 31-44, 2012.

[11] P. Hotaek, Y. Takeshi, and O. Takeshi, "Responses of Energy Budget and Evapotranspiration to Climate Change in Eastern Siberia, Evapotranspiration," Prof. Leszek Labedzki (Ed.), InTech, 2011, http://www.intechopen.com/books/evapotranspiration/responses-of-energy-budget-and-evapotranspirationto-climate-change-in-eastern-siberia.

[12] P. Campra, M. Garcia, Y. Canton, and A. Palacios-Orueta, "Surface temperature cooling trends and negative radiative forcing due to land use change toward greenhouse farming in southeastern Spain," Journal of Geophysical Research D, vol. 113, no. D18, Article ID D18109, 2008.

[13] M. Georgescu, D. B. Lobell, and C. B. Field, "Direct climate effects of perennial bioenergy crops in the United States," Proceedings of the National Academy of Sciences of the United States of America, vol. 108, no. 11, pp. 4307-4312, 2011.

[14] J. J. Feddema, K. W. Oleson, G. B. Bonan et al., "Atmospheric science: the importance of land-cover change in simulating future climates," Science, vol. 310, no. 5754, pp. 1674-1678, 2005.

[15] T. M. Saitoh, I. Tamagawa, H. Muraoka, and H. Kondo, "An analysis of summer evapotranspiration based on multi-year observations including extreme climatic conditions over a cool temperate evergreen coniferous forest Takayama, Japan," Hydrological Processes, vol. 27, no. 23, pp. 3341-3349, 2013.

[16] R. A. Pielke Sr., G. Marland, R. A. Betts et al., "The influence of land-use change and landscape dynamics on the climate system: relevance to climate-change policy beyond the radiative effect of greenhouse gases," Philosophical Transactions of the Royal Society A, vol. 360, no. 1797, pp. 1705-1719, 2002.

[17] B. Timbal and J. M. Arblaster, "Land cover change as an additional forcing to explain the rainfall decline in the south west of Australia," Geophysical Research Letters, vol. 33, no. 7, Article ID L07717, 2006.

[18] F. W. S. Correia, R. C. S. Alvalá, and A. O. Manzi, "Modeling the impacts of land cover change in Amazonia: a regional climate model (RCM) simulation study," Theoretical and Applied Climatology, vol. 93, no. 3-4, pp. 225-244, 2008.

[19] D. Li, M. Pan, Z. Cong, L. Zhang, and E. Wood, "Vegetation control on water and energy balance within the Budyko framework," Water Resource Research, vol. 49, no. 2, pp. 969-976, 2013.

[20] B. Chen, J. M. Chen, and W. Ju, "Remote sensing-based ecosystem-atmosphere simulation scheme (EASS)-Model formulation and test with multiple-year data," Ecological Modelling, vol. 209, no. 2-4, pp. 277-300, 2007.

[21] D. D. Baldocchi and D. R. Bowling, "Modelling the discrimination of ${ }^{13} \mathrm{CO}_{2}$ above and within a temperate broad-leaved forest canopy on hourly to seasonal time scales," Plant, Cell and Environment, vol. 26, no. 2, pp. 231-244, 2003.

[22] S. Jia, W. Zhu, A. Lu, and T. Yan, "A statistical spatial downscaling algorithm of TRMM precipitation based on NDVI and DEM in the Qaidam Basin of China," Remote Sensing of Environment, vol. 115, no. 12, pp. 3069-3079, 2011.

[23] H. Aksoy, Z. F. Toprak, A. Aytek, and N. E. Ünal, "Stochastic generation of hourly mean wind speed data," Renewable Energy, vol. 29, no. 14, pp. 2111-2131, 2004.

[24] T. X. Yue, Z. M. Fan, and J. Y. Liu, "Scenarios of land cover in China," Global and Planetary Change, vol. 55, no. 4, pp. 317-342, 2007. 
[25] Y. L. Xu and R. Jones, "Validating PRECIS with ECMWF reanalysis data over China," Chinese Journal of Agrometeorology, vol. 25, no. 1, pp. 5-9, 2004.

[26] F. D. Wang, Y. L. Xu, and T. Li, "Long term climate numerical simulation over china by regional climate model PRECIS," Chinese Journal of Agrometeorology, vol. 31, no. 3, pp. 327-332, 2010.

[27] S. W. Gou, Y. X. Zhang, and Y. L. Xu, "Analysis of climate resource changes during maize growth period in Ningxia under SRES A1B scenario," Chinese Journal of Eco-Agriculture, vol. 20, no. 10, pp. 1394-1403, 2012.

[28] X. Z. Shi, D. S. Yu, E. D. Warner et al., "Soil database of 1:1, 000, 000 digital soil survey and reference system of the chinese genetic soil classification system," Soil Survey Horizons, vol. 45, pp. 129-136, 2004.

[29] V. Mishra, K. A. Cherkauer, D. Niyogi et al., "A regional scale assessment of land use/land cover and climatic changes on water and energy cycle in the upper Midwest United States," International Journal of Climatology, vol. 30, no. 13, pp. 20252044, 2010.

[30] T. E. Twine, C. J. Kucharik, and J. A. Foley, "Effects of land cover change on the energy and water balance of the Mississippi River basin," Journal of Hydrometeorology, vol. 5, pp. 640-655, 2004. 

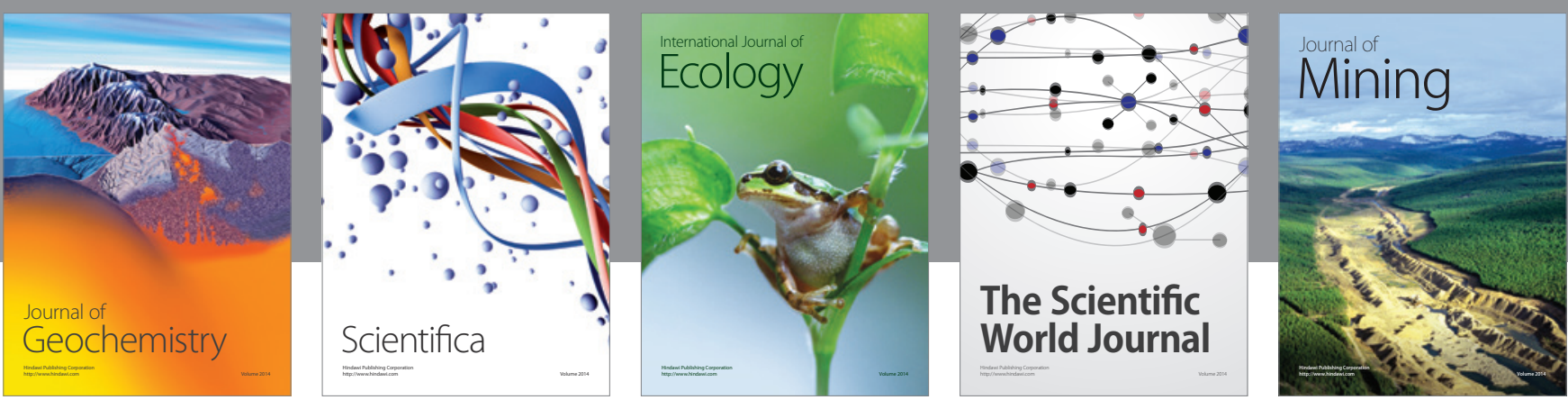

The Scientific World Journal
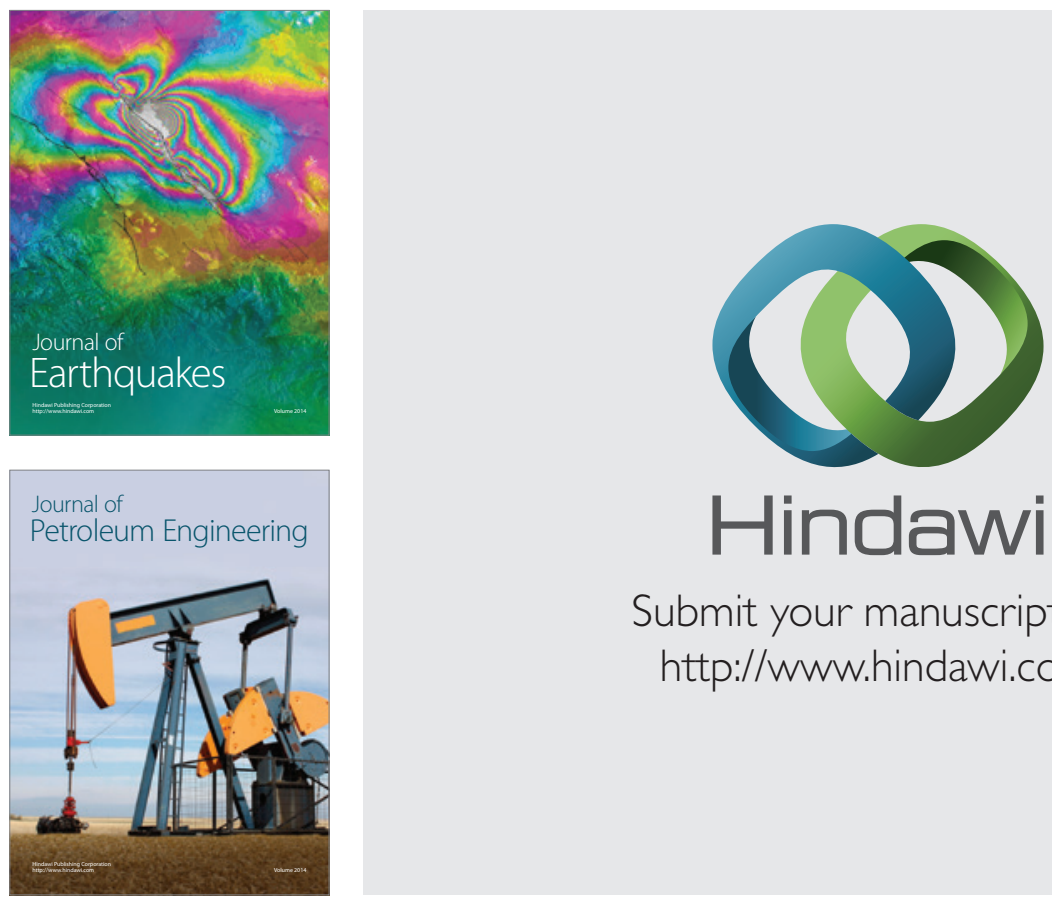

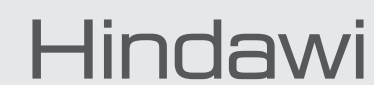

Submit your manuscripts at

http://www.hindawi.com
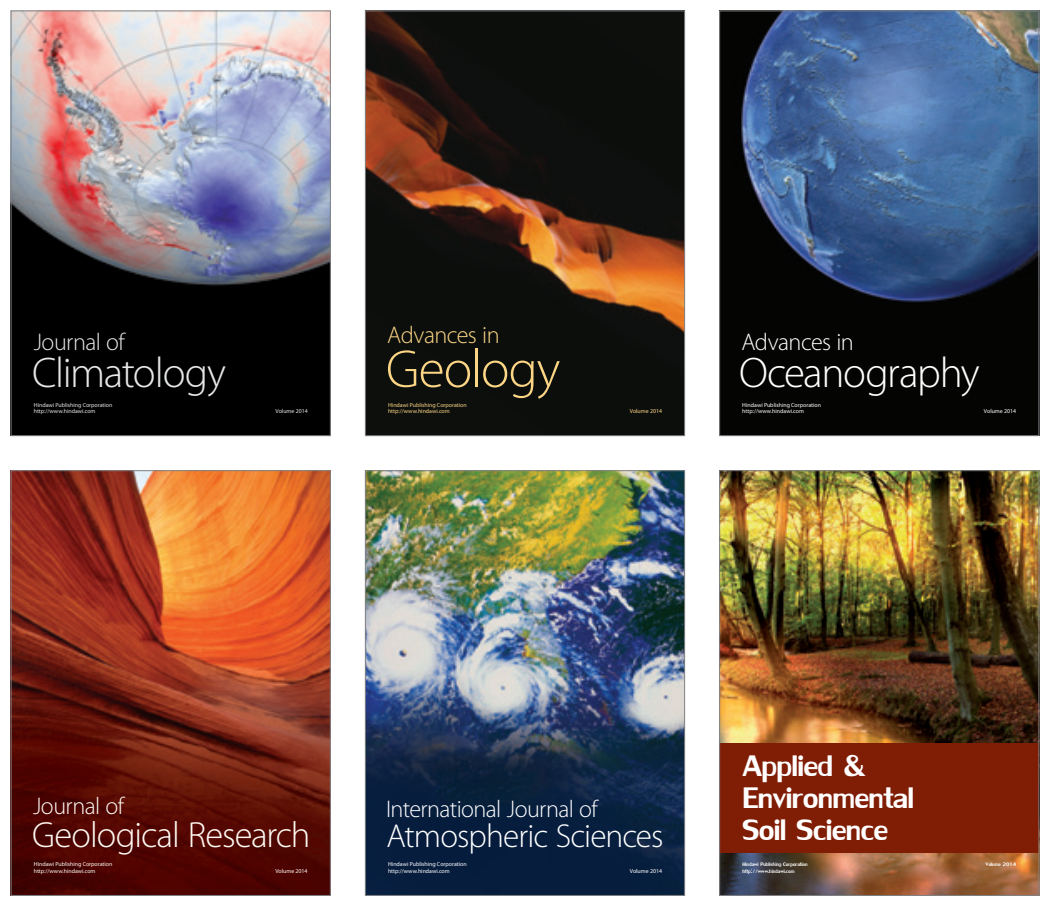
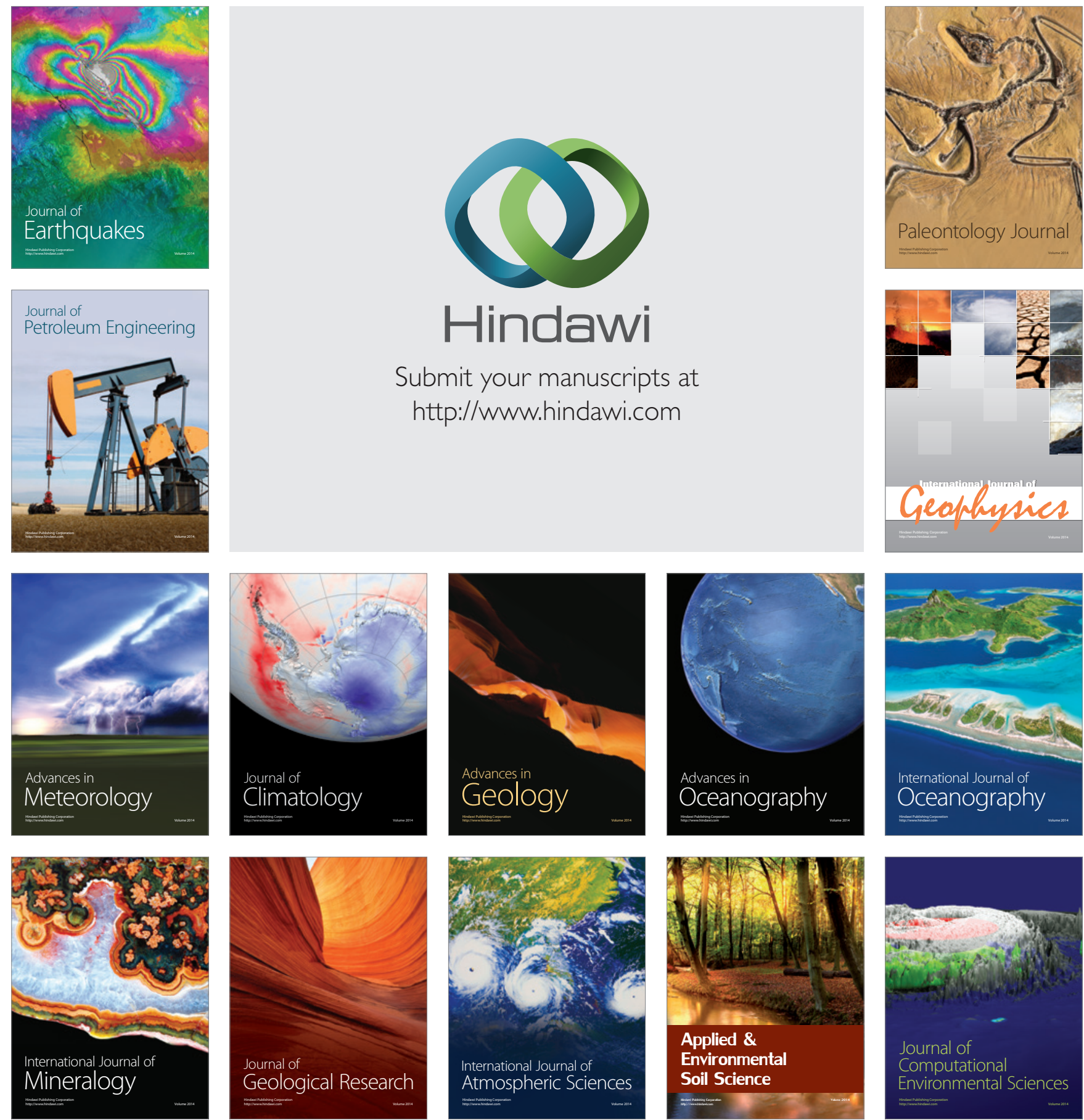